ORIGINAL ARTICLE

\title{
Comparison of MRI and CT for Detection of Acute Cerebral Haemorrahge
}

MEMONA NAZIR ${ }^{1}$, TAHIR BAIG ${ }^{2}$, ATIF HUSSAIN ${ }^{3}$, MUHAMMAD TAHIR $^{4}$, HAIDER ALI $^{5}$, MUHAMMAD NAUMAN AKRAM ${ }^{6}$

${ }^{1}$ Senior Registrar Radiology, Mohiuddin Islamic Medical College Mirpur AJK

${ }^{2}$ Assistant Professor Radiology, Rai Medical College, Sargodha

${ }^{3}$ Associate Professor Anatomy Women Medical and Dental College, Abbottabad

${ }^{4}$ Assistant Professor of Oncology Allied Hospital/ Faisalabad Medical University, Faisalabad

${ }^{5}$ Consultant Neurosurgeon, Lady Reading Hospital, Peshawar

${ }^{6}$ Assistant Professor Radiology, Sahara Medical College, Narowal

Corresponding author: Dr. Memona Nazir, Email: memonanazir12@gmail.com, Contact: +92 3345344359

\begin{abstract}
Objective: To compare the diagnostic accuracy of MRI and CT for detection of acute cerebral haemorrahge. Study Design: Comparative Study

Place and Duration: Mohiuddin Islamic Teaching Hospital Mirpur AJK for period of six months from $1^{\text {st }}$ August, 2020 to $31^{\text {st January, } 2021 .}$

Methodology: A total of 20 patients of both genders with age of 25 years and onward with intracerebral hemorrhage who underwent MRI following CT in the first 6 hours of onset and last known well time and admission in stroke center were included in the study. The follow up time duration for both the scans was 24 hours to 48hours. The Mc-Nemar test was used to determine the comparison between MRI and CT on contingency table. Results: The mean age of the participants was 53.26 \pm 2.45 . The frequency of the male participants was $13(65 \%)$ and that of female was $7(35 \%)$. All cases were of acute ICH $20(100 \%)$. The number of positive cases on MRI and CT scan was 17, while the frequency of positive cases on MRI and negative on CT scan was 3 with the $p$ - value of less than 0.001 and a confidence interval of $95 \%$. (See table 1 for details). The interrater reliability for acute $\mathrm{ICH}$ on $\mathrm{MRI}$ is from 0.72 to 0.80 on $\mathrm{k}$ statistics. The interrater reliability for acute ICH on CT is from 0.83 to 0.92 .

Conclusion: It is concluded that the findings of MRI scan were more accurate than CT in the detection of acute intracerebral hemorrhage.

Keywords: Acute Cerebral Hemorrhage, MRI, CT, Diagnostic Accuracy
\end{abstract}

\section{INTRODUCTION}

Intracerebral hemorrhage $(\mathrm{ICH})$ is a most fatal type of stroke that has morality rate of $40 \%$. It accounts of 10 to $15 \%$ of all strokes. Its incidence ranges from 11 to 23 per 100,000 cases per year. It can be classified to primary and secondary hemorrhages according to its etiological aspect.(1)

Primary hemorrhages are spontaneous and occurs due to arterial hypertension. Secondary hemorrhages are caused by traumas, tumors and some drugs(2). The exact pathophysiology of primary hemorrhages is unknown. The hematoma is generally located in basal ganglia, posterior fossa or thalamus. According to localization or etiology of hemorrhages, $\mathrm{ICH}$ causes neurological deficits within few minutes to hours(3). The common symptoms include vomiting, altered level of consciousness, contralateral paresis or sometime paralysis of arm, leg and aphasia and hemianopsia also occur(4).

The diagnosis of $\mathrm{ICH}$ is done by a series of neuroimaging techniques. Cranial Non-contrast computed tomography $(\mathrm{CT})$ is having higher sensitivity and is first choice of imaging technique for evaluating hemorrhages(5), however sometimes hemorrhages are not apparent on the CT that is why radiologists recommend magnetic resonance imaging (MRI) (T2 and proton weighted sequences) that helps in exact detection and diagnosis of type and location of $\mathrm{ICH}(6)$. A study done by Fiebach et al showed $100 \%$ sensitivity of $\mathrm{MRI}(7)$. Some previous studies have also reported the efficacy of MRI. T1 andT2 weighted MRI pulse sequences have higher sensitivity in the diagnosis of acute and chronic hemorrhages.(8)
The management of $\mathrm{ICH}$ requires several therapies(9). According to international surgical trials in intracerebral hemorrhages the with superficial hemorrhage ( distance to the surface of cortex of less than $1 \mathrm{~cm}$ ) should be treated surgically, while small hemorrhages with no neurological deficits should not be treated surgically(10, 11). Patients with low glasgow coma scale(GCS) less than 7 should be treated surgically. Some of surgical therapies are open craniotomy and evacuation of hematoma, computed tomography guided stereotaxy, endoscopic evacuation of hematoma $(12,13)$.

Despite of the fact that intracerebral hemorrhages are alarming situations yet its detection on time and evaluation of consequences is crucial. Therefore, there was dire need to conduct a study that compare the neuroimaging techniques(MRI and CT scan) for detection of ICH in order to reduce its worst consequences.

\section{METHODOLOGY}

A comparative study was conducted in the stroke center of Mohiuddin Islamic Teaching Hospital Mirpur, AJK for period of six months from $1^{\text {st }}$ August, 2020 to $31^{\text {st }}$ January, 2021. An ethical approval was taken from the research ethical review committee of the hospital. A total of 20 patients of both genders with age of 25 years and onward with intracerebral hemorrhage who underwent MRI following CT in the first 6 hours of onset and last known well time and admission in stroke center were included in the study. Patients presenting with coma, pacemaker, symptoms of subarachnoid hemorrhage, other contraindications to MRI, 
initiation of thrombolytics, anticoagulants and cardiorespiratory distress were excluded from the study.

Imaging parameters: The MRIs(T2 gradient recalled echo, GRE) were performed on 1.5T scanners equipped with echoplanar imaging capability. The scanners used following pulse sequences. $7 \mathrm{~mm}$ slice thickness (T2, GRE), repetition time of $800 \mathrm{Ms}$. Flip angle of 30 degree (GRE) acquisition matrix of $256 \times 192$ (GRE).

The CT scans were performed with fourth generation scanner such as high-speed advantage scanner. The images were obtained by orbito-metal plane with $5 \mathrm{~mm}$ of thickness for examination.

The order of the films was randomized and differed for each scan (MRI and CT Scan), both the scans were performed on different days in order to avoid confusion for the investigator. A panel of 4 readers (2 neuroradiologists, 2 neurologists) were decided to analyze the films and decide that which scan has provided more accurate diagnosis. The panel was blinded to the clinical information and all patients' identifiers.

Follow up duration: The follow up time duration for both the scans was 24 hours to 48hours.
Statistical tests: The Mc-Nemar test was used to determine the comparison between MRI and CT on contingency table. While the interrater reliability was checked by K-statistics with the confidence interval of $95 \%$ and $5 \%$ of margin of error.

\section{RESULTS}

The study recruited a total of 25 patients, as per inclusion criteria 20 patients having acute $\mathrm{ICH}$ were enrolled in the study. The panel of 4 reader identified each and every scan with care and experience. The patients had follow-up of $\mathrm{MRI}$ and CT for $24 \mathrm{hr}$ to $48 \mathrm{hr}$. The mean age of the participants was $53.26 \pm 2.45$. The frequency of the male participants was $13(65 \%)$ and that of female was $7(35 \%)$. All cases were of acute ICH 20(100\%).

The number of positive cases on MRI and CT scan was 17 , while the frequency of positive cases on MRI and negative on CT scan was 3 with the $p$ - value of less than 0.001 and a confidence interval of $95 \%$. (See table 1 for details). The interrater reliability for acute $\mathrm{ICH}$ on $\mathrm{MRI}$ is from 0.72 to 0.80 on $\mathrm{k}$ statistics. The interrater reliability for acute $\mathrm{ICH}$ on CT is from 0.83 to 0.92 .

Table 1: Showing the comparison of positive and negative cases ofMRI and CT scan

\begin{tabular}{|l|l|l|l|l|}
\hline Acute ICH & $\mathrm{CT}+$ & $\mathrm{CT}-$ & Total & P-value \\
\hline $\mathrm{MRI}+$ & $17(85 \%)$ & $3(15 \%)$ & $20(100 \%)$ & $<0.001$ \\
\hline $\mathrm{MRI}-$ & 0 & 0 & 0 & \\
\hline
\end{tabular}

\section{DISCUSSION}

A number of neurological imaging techniques are available for the evaluation of extent of intracerebral hemorrhage(14). However, MRI and CT have its own importance among all. Though the CT scan is having better reliability in detecting hemorrhages but when it comes to MRI the reproducibility of it is excellent in detection of different kind of hemorrhages $(15,16)$.

The aim of the current study was to compare MRI and CT for acute intracerebral hemorrhage. the study included only 20 patients (10 male and 10 female) that have undergone MRI followed by CT within 6 hours of onset. The results of the study shown that MRI (T2 GRE) was more accurate in detecting hemorrhage.

The results of the Arnould et al were similar to the current study in which MRI (T2 GRE) was found to be more accurate and had higher reproducibility than CT scan. This accuracy is due to the paramagnetic effect of methemoglobin and deoxyhemoglobin that allows detection of blood as hypo intensity within ischemic field(17).

The study of P. Renou et also showed that MRI (T2 GRE ) was more accurate than CT scan in detecting hemorrhagic transformations. The non-contrast CT is considered as gold standard for detecting intracerebral hemorrhages but in the study of P.Renou the CT had poor to moderate reliability in bleeding detection while T2 GRE had excellent reproducibility, their study findings were concordant to the present study in which MRI showed more accuracy in detection of $\mathrm{ICH}(18)$.

Another study conducted by Chelsea et al on the comparison of $\mathrm{MRI}$ and CT in detection of any type of hemorrhage showed that MRI(DWI, T2 GRE) had identified hemorrhages accurately than non-contrast CT, which was inline to the present study. Their study showed 4 positive cases of intracerebral hemorrhages which were not apparent on CT(19).

The study of Rajiv Gupta et al showed contrast results to the current study in which he has identified the worth of CT scan over any other neuroimaging technique. Rajiv further said that unenhanced CT is the standard of care for the detection of intracerebral hemorrhages after intraarterial therapy(20).

Almost all the literature found were in the favor of use of $\mathrm{MRI}$ for detecting $\mathrm{ICH}$ rather than CT scan. Many neuroradiologists recommend $\mathrm{MRI}$ as a choice of detection tool for evaluating any type of hemorrhages.

\section{CONCLUSION}

The study concluded that the findings of MRI scan were more accurate than CT in the detection of acute intracerebral hemorrhage.

Conflict of Interest: The author didn't find any conflict of interest regarding the study.

\section{REFERENCES}

1. Reichart R, Frank S. Intracerebral hemorrhage, indication for surgical treatment and surgical techniques. The Open Critical Care Medicine Journal. 2011;4(1).

2. Kirkman M, Mahattanakul W, Gregson B, Mendelow A. The effect of the results of the STICH trial on the management of spontaneous supratentorial intracerebral haemorrhage in Newcastle. British journal of neurosurgery. 2008;22(6):73946.

3. Caceres JA, Goldstein JN. Intracranial hemorrhage. Emergency medicine clinics of North America. 2012;30(3):771.

4. Qureshi Al, Mendelow AD, Hanley DF. Intracerebral haemorrhage. The Lancet. 2009;373(9675):1632-44. 
5. Kuo W, Häne C, Mukherjee P, Malik J, Yuh EL. Expert-level detection of acute intracranial hemorrhage on head computed tomography using deep learning. Proceedings of the National Academy of Sciences. 2019;116(45):22737-45.

6. Kassner A, Roberts T, Taylor K, Silver F, Mikulis D. Prediction of hemorrhage in acute ischemic stroke using permeability MR imaging. American Journal of Neuroradiology. 2005;26(9):2213-7.

7. Fiebach JB, Schellinger PD, Gass A, Kucinski T, Siebler M, Villringer $A$, et al. Stroke magnetic resonance imaging is accurate in hyperacute intracerebral hemorrhage: a multicenter study on the validity of stroke imaging. Stroke. 2004;35(2):502-6.

8. Allkemper $\mathrm{T}$, Tombach B, Schwindt $\mathrm{W}$, Kugel $\mathrm{H}$, Schilling $\mathrm{M}$ Debus $O$, et al. Acute and subacute intracerebral hemorrhages: comparison of MR imaging at 1.5 and 3.0 Tinitial experience. Radiology. 2004;232(3):874-81.

9. Sahni R, Weinberger J. Management of intracerebral hemorrhage. Vascular health and risk management. 2007;3(5):701.

10. Elliott J, Smith M. The acute management of intracerebral hemorrhage: a clinical review. Anesthesia \& Analgesia. 2010;110(5):1419-27.

11. Adeoye O, Broderick JP. Advances in the management of intracerebral hemorrhage. Nature Reviews Neurology. 2010;6(11):593.

12. Thabet A, Kottapally M, Hemphill III JC. Management of intracerebral hemorrhage. Handbook of clinical neurology. 2017;140:177-94.
13. Chan S, Hemphill JC. Critical care management of intracerebral hemorrhage. Critical care clinics. 2014;30(4):699-717.

14. Meyer-Wiethe K, Sallustio F, Kern R. Diagnosis of intracerebral hemorrhage with transcranial ultrasound. Cerebrovascular Diseases. 2009;27(Suppl. 2):40-7.

15. Hostettler IC, Seiffge DJ, Werring DJ. Intracerebral hemorrhage: an update on diagnosis and treatment. Expert review of neurotherapeutics. 2019;19(7):679-94.

16. Morotti A, Goldstein JN. Diagnosis and management of acute intracerebral hemorrhage. Emergency medicine clinics of North America. 2016;34(4):883.

17. Arnould M-C, Grandin CB, Peeters A, Cosnard G, Duprez TP. Comparison of CT and Three MR Sequences for Detecting and Categorizing Early (48 Hours) Hemorrhagic Transformation inHyperacute Ischemic Stroke. American journal of neuroradiology. 2004;25(6):939-44.

18. Renou P, Sibon I, Tourdias T, Rouanet F, Rosso C Galanaud D, et al. Reliability of the ECASS radiological classification of postthrombolysis brain haemorrhage: a comparison of CT and three MRI sequences. Cerebrovascular Diseases. 2010;29(6):597-604.

19. Kidwell CS, Chalela JA, Saver JL, Starkman S, Hill MD, Demchuk AM, et al. Comparison of MRI and CT for detection of acute intracerebral hemorrhage. Jama. 2004;292(15):1823-30.

20. Gupta R, Phan CM, Leidecker C, Brady TJ, Hirsch JA, Nogueira RG, et al. Evaluation of dual-energy $C T$ for differentiating intracerebral hemorrhage from iodinated contrast material staining. Radiology. 2010;257(1):205-11. 